\title{
Continued Efforts in TI ARM M4 Microcontroller Curricula Developments and Assessments between Three Different Institutions and Programs
}

\section{Dr. Steve C. Hsiung, Old Dominion University}

Steve Hsiung is a professor of electrical engineering technology at Old Dominion University. Prior to his current position, Dr. Hsiung had worked for Maxim Integrated Products, Inc., Seagate Technology, Inc., and Lam Research Corp., all in Silicon Valley, CA. Dr. Hsiung also taught at Utah State University and California University of Pennsylvania. He earned his BS degree from National Kauhsiung Normal University in 1980, MS degrees from University of North Dakota in 1986 and Kansas State University in 1988, and PhD degree from Iowa State University in 1992. Steve can be reached at shsiung@odu.edu.

\section{Dr. Lijian Xu, State University of New York, Farmingdale}

Dr. Xu has 12 years of engineering and engineering management experience from AT\&T and Telus Communication. Dr. Xu taught electrical and computer engineering courses at Wayne State University from 2009 to 2014. He joined Farmingdale State College from 2014. His research interests are in the areas of cyber-physical systems, FGPA design, digital wireless communication, stochastic analysis. His research to date has involved the impact of wireless communication in the feedback systems. Additionally, his research in tracking has involved cyber-physical uncertainties in wireless networked sensing and control, network resource allocation, platoon control and smart grid.

\section{Dr. Feng Jao, Ohio Northern University}

Feng Jao, Ph.D., is an Associate Professor of Technology at Ohio Northern University. She has been teaching courses in the area of Computer Applications and Information Technology. Her areas of interests include 3D CAD sketch, 3D printing, Hybrid Learning Instructional Design, Digital Media, Interactive Media, Instructional Technology Integration and network design. In addition, Dr. Jao is a certified Microsoft Office Master Instructor, and Cisco Certified Network Associate (CCNA).

\section{Dr. Yonghui Wang, Prairie View A\&M University}

Dr. Yonghui Wang received his B.S. in Optoelectronics from Xidian University in 1993, his M.S. in electrical engineering from Beijing Polytechnic University in 1999; and his Ph.D. in computer engineering from Mississippi State University in 2003. From 1993 to 1996, he was a Research Engineer with the 41st Electrical Research Institute in Bengbu, China. From July 1999 to December 1999, he worked as an IT Specialist in IBM China, Beijing, China. From 2000 to 2003, he was a research assistant with the Visualization, Analysis, and Imaging Laboratory (VAIL), the GeoResources Institute (GRI), Mississippi State University. He is currently an Associate Professor with the Department of Engineering Technology, Prairie View A\&M University. His research interests include digital signal processing, image and video coding, and wavelets.

\section{Dr. Suxia Cui, Prairie View A\&M University}

Suxia Cui is an associate professor in the Department of Electrical and Computer Engineering at Prairie View A\&M University (PVAMU). She joined PVAMU right after she obtained her Ph.D. degree in Computer Engineering from Mississippi State University in 2003. Her research interests include image and video processing, data compression, wavelets, computer vision, remote sensing, and computing education. Her projects are currently funded by NSF, United States Department of Agriculture, and Department of Education. 


\section{A Continued Effort in TI ARM M4 Microcontroller Curricula Development and Assessment between Three Different Institutions and Programs}

\section{Introduction}

This article addresses curriculum design activities that are based on the initiatives from NSF funded projects that focused on cyber-enabled collaborative learning in the academic community. The curriculum development initiatives addressed the disappearance of the popular 68XXX and 80XXX microcontroller and microprocessor families. These aging microcontrollers and microprocessors have become an instructional issue and concern in the engineering education community. Everyone agrees that technological change in microcontroller and microprocessor development is inevitable. However, there are issues and challenges in choosing which family of microcontrollers to select, such as Microchip PIC, Arduino ATMEL, ARM etc. for engineering education and training.

The Texas Instruments (TI) ARM M4 microcontroller was selected because the NSF I-Corp $\mathrm{L}$ project results indicated that the academic community needed a new advanced microcontroller platform to meet industry technical training demands [1]. The TI ARM M4 based curriculum design and development project illustrates how the collaborative efforts between faculty at different institutions can be beneficial in developing instructional materials that lead to effective teaching and improved student learning. There are several other collaborative issues and concerns that were addressed in the results of the NSF I-Corp L project. These included a variety of teaching formats such as face-to-face instruction in traditional classrooms, online Internet-based instruction, and realtime hands-on instruction in a distance delivery format. Cyber enabled learning takes many shapes and forms. It is commonly described as Distance Learning, Hybrid Learning, eLearning, or online learning [2]. While there are many terms used to describe Internet-based learning, it can be used as stand-alone online instruction or used in conjunction with traditional face-to-face instruction. This learning environment offers real-time distance learning experience and provides learners the availability of asynchronous course materials that assist learning 24/7 via archived database [3]. It provides a wide range of opportunities in the on-line learning community for teacher-student experiences as well as student-to-student and student group learning experiences. Most importantly, it enables educators to collaborate in a distance environment regardless of geographical location. Educators can share experiences, develop programs, collaborate in research activities, and improve faculty professional development. This article illustrates examples of collaboration between faculty located in different locations that shared common teaching goals and experiences to improve student learning.

\section{The Collaborated Efforts}

The collaborative effort originated by Old Dominion University (ODU) faculty in Norfolk, Virginia in cooperation with Farmingdale State College (FSC), Farmingdale, New York faculty as a team effort for the design and development of course and lab modules based on the Texas Instruments' Tiva C Series LaunchPad [4] with the ARM Cortex-M4 microcontroller in related 2016-2018 courses. Subsequently, Prairie View A\&M University (PVAMU), Prairie View, Texas faculty were invited to join the collaboration in 2018 with their courses. COSMIAC research center at the University of New Mexico [5] provided assistance in the development of instructional materials for TI the LauchPad with TM4C123 ARM M4 [6] and [7] in conjunction with several textbooks. The text references included Dr. Johnathan Valvano's "Embedded Systems: Real-Time Interfacing to the Arm Cortex-M3" [9] and "Real-Tine Interfacing to ARM 
Cortex-M Microcontrollers, $2^{\text {nd }}$ Edition" [10] at the University of Texas in Austin, and Dr. Muhammad Mazidi's “TI TIVA ARM Programming for Embedded Systems: Programming ARM Cortex-M4 TM4C123G with C" [11]. The dissemination of the instructional material was made through a Learning Management System (LMS) [12] that was hosted by an independent private hosting company and designed and managed by Ohio Northern University (ONU) faculty. The assessment of student learning and feedback included senior students at ODU's Electrical Engineering Technology (EET) program, FSC's Electrical Engineering Technology (EET) majors, and PAVAMU's Computer Engineering Technology (CPET) majors and Electrical and Computer Engineering (ELEG) students that were introduced to this new microcontroller for the first or second time in either a traditional on-campus face-to-face environment or synchronous distance delivery.

\section{Common Hardware and Software Platform}

Collaboration in course and faculty professional development and deliverable content through synchronous distance learning requires a common hardware and software platform as fundamental components. An $u C$ Training System was designed and implemented based on a PIC training system that was developed through previously funded NSF projects [13]. The $u C$ Training System hardware has the capability to integrate the TI Tiva C Series LaunchPad (TM4C123G microcontroller) and perform the same as well as new experiments as compared to the PIC microcontrollers. A comparison of the features and differences between the microcontrollers is available on www.ucdistancetraining.org web site under the "What's New" option. The free microcontroller development software that is readily available and downloadable from manufacturer web sites, www.microchip.com or www.ti.com, is an important factor to consider in developing instructional materials. In our case, the TI software was the most appropriate choice of software to use for our collaborative curriculum project. All of the guides and step-by-step procedures for downloading the software and hardware manuals are provided through the Learning Management System used for collaboration and is accessible by teachers and students. A significant consideration is the importance of the common platform, $u C$ Training System hardware, and dissemination web site that are necessary for achieving effective and realistic collaboration experiences. The common platform for the $u C$ Training System and TI Tiva LaunchPad is shown in Photo 1 that was used in the lecture and lab classes at ODU, FSC, and PVAMU.

\section{Design and Development of the Curricula Modules}

The course modules were developed by researching and reviewing available software, hardware, data sheets from Texas Instruments, other technical reference materials [6], [7], and [8] and books[9], [10], and [11]. The goal was to take the complex material and concepts and synthesize that content into a sound instructional format that can be used directly as class and laboratory lecture material. The collaborative efforts resulted in different course and lab modules that can be implemented directly in traditional class lecture and discussion format or in a realtime distance teaching environment. The initial labs were developed from Texas Instruments' "Getting Started with Tiva Launchad" [6] and COSMIAC workshop material [5] and further refined and formatted into more detailed step-by-step guides that students can follow. All the course materials were tested by faculty at ODU and FSC before being disseminated through the project LMS platform. Faculty at ODU developed the initial lecture material and several lab modules. FSC and PVAMU faculty added additional labs with same format that are deliverable 
as distance learning products through an LMS or traditional handouts. It is important to realize that the objectives of the collaborative initiative were not to cause confusion or conflict in either on-campus or distance offerings at different institutions. All the available course and lab modules are available at www.ucdistancetraing.org.

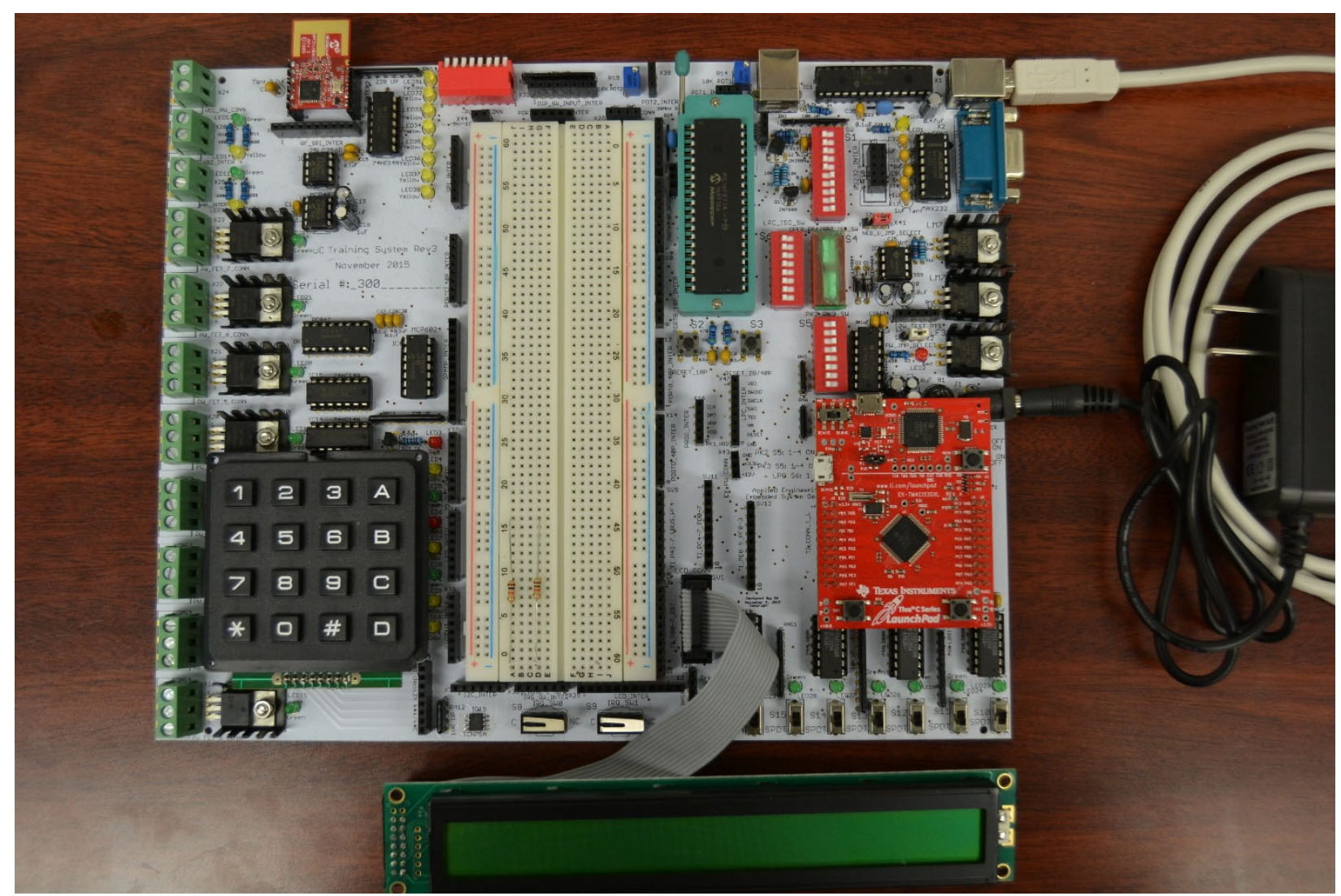

Photo 1. uC Training System and TI Tiva LaunchPad

\section{Implementation Strategies and Planning for On-Campus and Distance Hands-on Approach}

The EET 470 "Microprocessor/Microcontroller Based Designs" offered at ODU is a senior elective course offered in a real-time, hands-on distance delivery format where instructor lectured via Adobe Connect web-based video conferencing application. All the lectures were recorded and accessible online to students without restriction. All students were given handouts and homework assignments via Blackboard or the project LMS that were based on fixed hardware on the TI Tiva C Series LaunchPad and $u C$ Training System with appropriate interfacing to peripheral hardware. Students were required to prepare $\mathrm{C}$ code designs with specified functions that must work with the ARM M4 platform. The software was based on TI C Code Composer Studio (CCS) [14] with the factory function libraries. The students verified their software designs on the specified hardware and turned in their $\mathrm{C}$ code designs according to the assignment requirements and schedule. The instructor checked the student's code assignment by running it on the same hardware and interface peripherals and graded the work based on the end performance on the hardware.

The hands-on exercises included basic I/O controls, SPI to EEPROM (25LC256) [15] and $2.4 \mathrm{GHz}$ RF wireless module (MRF24J40MA) [16], $\mathrm{I}^{2} \mathrm{C}$ to temperature sensor - TCN75A [17] communications, different microcontrollers (MCUs) (between PIC and ARM M4 MCUs), 
display devices, and communication protocols. Technical difficulties were resolved through oneon-one video conferencing sessions using Adobe Connect [19] in much the same manner as student assistance that may be provided through faculty office-hour appointments or meetings. It is important to note that this is a senior elective course and that the student is expected to have previous experiences with microcontrollers and have completed EET 320: Microprocessors and Microcontrollers and EET 325: Microprocessor Laboratory before taking this class.

FSC faculty offered their EET 418 class which is similar in content and experiences to ODU's EET 470 class, but presented it in a traditional on-campus, face-to-face format. The Farmingdale State College EET 418 "Microprocessor Interfacing and Control" is a senior required course for both electrical and computer engineering technology students at FSC. Students are required to take EET 251 "Microprocessor" and EET 110 "Introduction to Computer Application" before registering EET 418. All students were given lab exercises based on the hardware interfaces available on TI Tiva C Series LaunchPad and $u C$ Training System. There were 11 labs implemented in the EET418 "Microprocessor Interfacing and Control" class in two different sessions taught by different instructors.

Two departments from PVAMU participated in this project. They both are part of the College of Engineering at PVAMU. One is Electrical and Computer Engineering department where ELEG 4253 "Embedded Systems Design" is a senior level course required for the Computer Engineering program. It also serves as a technical elective for Electrical Engineering. The catalog course description specifically mentions the emphasis on student projects. With the adoption of the TI Tiva C Series LaunchPad and $u C$ Training System, students were able to get more hands-on practice. The course is taught in a traditional on-campus face-to-face format. Another PVAMU department, Computer Engineering Technology, offered CPET4051/4053 "Computer Systems Design and Lab." The course pair CPET4051/4053 are co-requisite to each other. CPET4053 is the lecture part, which focuses on the theory part while CPET4051 is the lab part, which focuses on the hands-on exercises. The courses were offered in a traditional oncampus, face-to-face format and are required senior level courses for computer engineering technology students at PVAMU. Before taking this course pair, students are required to successfully complete CPET3061/3063 “Computer Architecture." Students learned the theory of ARM M4 based embedded systems in CPET4053, and then practiced hands-on experiments in CPET4051. All hands-on labs were based on the hardware interfaces available on TI Tiva C Series LaunchPad and $u C$ Training System and Discovery kit with STM32L476VG MCU. There were 10 labs which included basic I/O controls, interrupts, and peripheral interfacing. The students were required to prepare $\mathrm{C}$ code designs and software using the Texas Instruments' C Code Composer Studio (CCS) or the KEIL $\mu$ Vision IDE. Most of the lab programming experiences were run in a debug mode. All students were required to code in C using the TI CCS environment and execute their program code on the hardware directly.

The following is a list of the hands-on activities that were implemented either in homework or laboratory assignment formats in the courses at ODU, FSC, and PVAMU:

1. Introduction to TI Tiva Launchpad w uC Trainer

2. TI Tiva C Series LaunchPad ARM M4 Hardware and Software Setup

3. Flashing LEDs Control with Tiva $u C$ Trainer

4. GPIO and LEDs Control

5. Interrupts and the Timer 
6. Stepper Control w Tiva uC Trainer

7. Parallel Communication with a LCD Module

8. 4*4 Keypad Scanning, Debouncing, and Decoding

9. ADC12

10. Generate SOS type coding via Tiva $u C$ Trainer

11. Hibernation Mode

12. Floating Point

13. Lower Power Modes

14. USB

15. PWM

\section{Dissemination Approach to the Academic Community}

The primary mechanism used to disseminate the instructional materials is the project web portal at www.ucdistancetraining.org. The project web portal serves as the central location for users to access instructional materials. The website provides not only general information for all users and but also includes instructional material for educators as member-based information requiring secure access. The structure of the project website is shown in Figure 1 and includes hardware and software product information, project videos, previous workshop information, community partners, course curriculum, FAQ, contact information, and a resource download page.

The resource page includes downloadable links for software applications such as an Initial Trainer Test, MPLAB IDE, XC8, PICKit2, TI ARM M4, Arduino, and PIC/uC Training System manuals. Users can download the software applications and follow by step-by-step installation guides for system setup that are considered necessary to start their learning process. They can communicate with the instructor through a variety of media technologies such as telephone communication, email, or face-to-face video conferencing for individual assistance as needed. It was also realized that the learner's capability to communicate with the researchers directly was a very important consideration for a successful learning experience. Consequently, instructions for using on-line video conferencing applications are included on the web site to assist learners in properly setting up their audio and video equipment.

The secured instructional materials for teachers and faculty are in the curriculum section of the Learning Management System (LMS) that is hosted on the web portal. Teachers and faculty who desire to access these instructional materials must submit a permission request to the webmaster. The webmaster and other team members will review the request to verify the requestor credentials and their eligibility based on the requestor's status and thus to grant or deny their access. When access is granted, the user will be provided with user account and password to access the curriculum modules in the LMS. Access to the curricula materials is restricted to teachers and faculty. All other materials such as data sheets, manuals, demonstration videos, step-by-step instructions on how to use the PIC and ARM M4 hardware are free and accessible to any interested users. Typically, students at other institutions can access these resource materials.

The LMS on-line community environment provided learners with the opportunity to view instructional videos to learn new topics, download programming code in a variety of programming languages, and download instructional materials and lab modules. The online forum provided the opportunity for learners to communicate with other users and share their project ideas and comments. 
Additionally, another collaborative project is accessible on the LMS web portal that describes an autonomous Arduino-based Rover vehicle. This project illustrates a collaborative effort for a summer camp project for approximately 30 tenth and eleventh grade high school students. The complete project information is posted in the web portal. Learners can access Arduino Rover and 3D printer tutorials through the home page on the web portal. Additionally, users can access detailed project information to recreate the project using the materials provided. The tutorial information includes project photos, project descriptions, and step-by-step instructions. These tutorials are open to all audiences where all instructional materials are accessible. They are categorized as follows:

- 3D Production Files for Rover

- Sample Arduino Programs

- Rover Robot Assembly

- Preparing the 3D Printer

- Assembling the Rover Chassis

- Connecting and programming Arduino

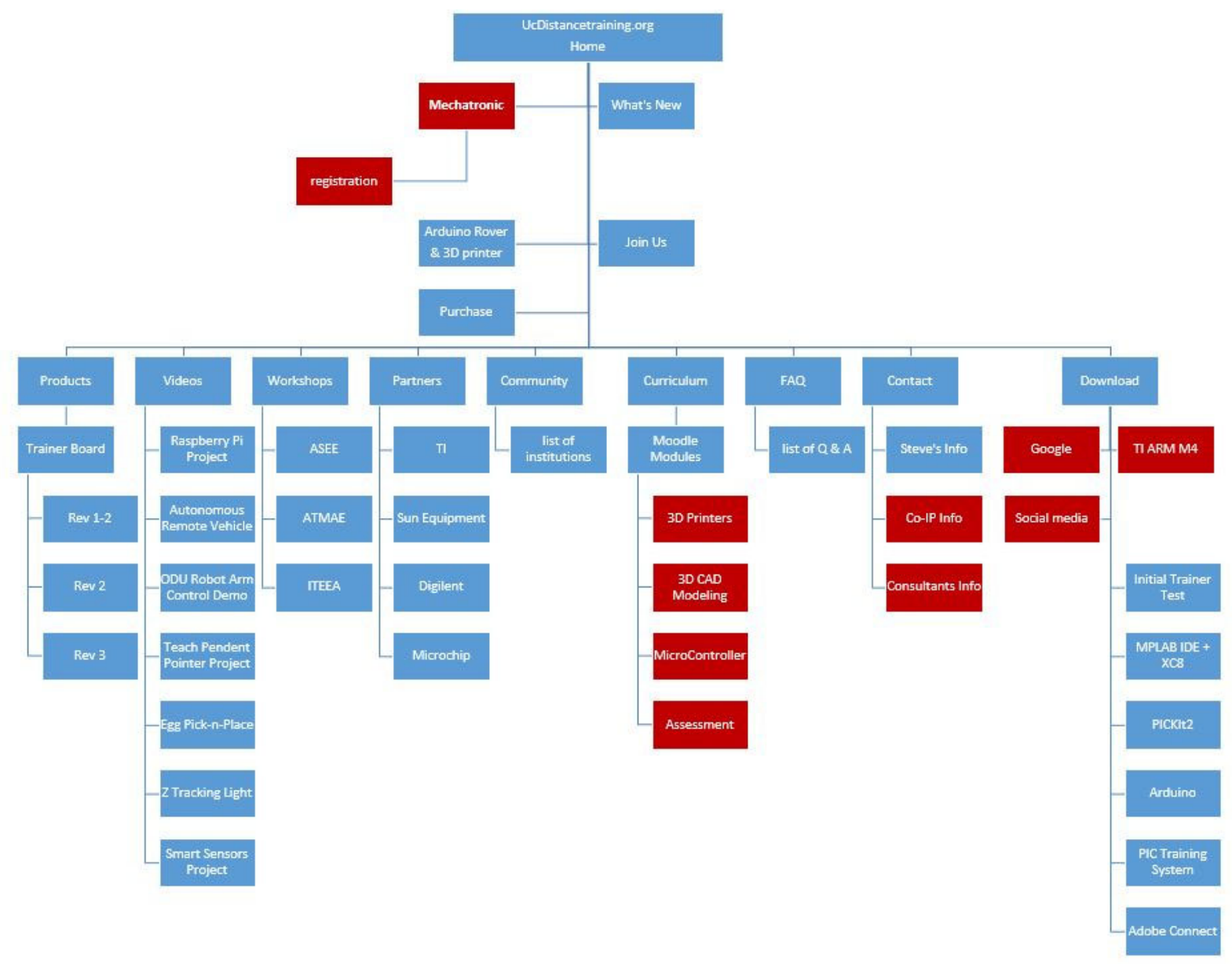

Figure 1. The LMS (Learning Management System) Platform 


\section{Preliminary Assessments of the Teaching and Learning at ODU, FSC, and PVAMU}

A simple preliminary ten-question questionnaire was designed and implemented to assess the effectiveness of the collaborative professional development experience and teaching efficiency of these new subjects taught during 2016-2018 at different institutions. The purpose of the questionnaire was to identify the effect of the change from PIC to ARM M4 microcontrollers and the change in software design from PIC Assembly (ASM) and C to C language used with ARM M4 controllers and determine if they are appropriate and effective. Additionally, the student's learning experience on the $u C$ Training System and TI Tiva LaunchPad is also a strong interest to the instructors. Question \#10 is an open-ended question that is intended for the instructor's self-assessment that reads "State some suggestions/implementations for this class" is not reported in the following data tables.

The questionnaire was distributed to students at ODU, who enrolled in EET 470: Microprocessor Based Design that incorporated the ARM M4 microcontroller platform in the fall semesters of 2016 and 2018. This EET470 is a senior elective course in distance format delivered in real-time where EET320/325: Microprocessor and Microcontroller/Laboratory are the perquisites for this elective course. All students had previous experiences in using PIC microcontroller software and hardware in ASM coding. The $\mathrm{C}$ programming experience was not required and thus provides a rationale explaining why this course must start with a PIC MCU in advanced subjects such as SPI, $\mathrm{I}^{2} \mathrm{C}, \mathrm{ADC}$, and wireless communication in ASM first, then introduce $\mathrm{C}$ coding, then migrate to TI ARM M4 MCU. All the hands-on exercises were assigned as in a homework format and required to be implemented on the $u C$ Training System platform and verified by the instructor with the required hardware interface. Under the course structure, where it limits the implementation of ARM MCU and C coding in the beginning of the EET470 at ODU. The data presented in Tables 1 are the combination of questionnaires and response results from 10 and 8 senior students in year of 2016 and 2018 respectively, where the courses were taught by the same instructor.

Table 1. ODU Students' Survey Results: EET470 in Years of 2016 and 2018

\begin{tabular}{|c|c|c|c|c|c|}
\hline \multirow[t]{2}{*}{ \# } & \multirow[t]{2}{*}{ Question } & \multicolumn{4}{|c|}{$\mathbf{N}=\mathbf{1 8}$} \\
\hline & & \multicolumn{3}{|c|}{ Yes } & No \\
\hline 1 & $\begin{array}{l}\text { Do you have previous experience of using high level language such } \\
\text { as C or CPP? }\end{array}$ & \multicolumn{3}{|c|}{$10(56 \%)$} & $8(44 \%)$ \\
\hline 2 & $\begin{array}{l}\text { Did you use high level language in the interfacing control } \\
\text { application in other classes or curriculum? }\end{array}$ & \multicolumn{3}{|c|}{$9(50 \%)$} & $9(50 \%)$ \\
\hline 3 & $\begin{array}{l}\text { Do you think it is effective and necessary of using } \mathrm{C} \text { to do the } \\
\text { hardware interfacing control applications? }\end{array}$ & \multicolumn{3}{|c|}{$18(100 \%)$} & $\mathbf{0}$ \\
\hline 4 & $\begin{array}{l}\text { Do you think the communications interfacing between the C/CPP } \\
\text { and ASM on an ARM M4 will be beneficial to you? }\end{array}$ & \multicolumn{3}{|c|}{$18(100 \%)$} & $\mathbf{0}$ \\
\hline 5 & $\begin{array}{l}\text { After learning the materials in EET470, are you capable to use high } \\
\text { level language (C) and ASM in the bits and bytes control } \\
\text { applications? }\end{array}$ & \multicolumn{3}{|c|}{$18(100 \%)$} & $\mathbf{0}$ \\
\hline 6 & $\begin{array}{l}\text { Do you like to see more applications of C/CPP in EET470? What } \\
\text { are those subjects? }\end{array}$ & \multicolumn{3}{|c|}{$15(83 \%)$} & $3(17 \%)$ \\
\hline \multirow[t]{2}{*}{7} & \multirow{2}{*}{$\begin{array}{l}\text { How much ARM M } 4 \text { should be introduced in the EET470? } 20 \% \text {, } \\
50 \%, 100 \% \text {, or Not at all }\end{array}$} & $20 \%$ & $50 \%$ & $100 \%$ & \multirow[t]{2}{*}{$\mathbf{0}$} \\
\hline & & $\begin{array}{c}6 \\
(33 \%)\end{array}$ & $\begin{array}{c}7 \\
(39 \%)\end{array}$ & $\begin{array}{c}5 \\
(28 \%) \\
\end{array}$ & \\
\hline \multirow[t]{2}{*}{8} & \multirow{2}{*}{ Do you think the $\mathrm{C}$ should be concentrate on PIC C or ARM M4? } & PIC & Both & ARM & \multirow[t]{2}{*}{$\mathbf{0}$} \\
\hline & & $\begin{array}{c}2 \\
(12 \%)\end{array}$ & $\begin{array}{c}8 \\
(44 \%)\end{array}$ & $\begin{array}{c}8 \\
(44 \%)\end{array}$ & \\
\hline
\end{tabular}


9 Do you think the $u C$ Training System assisted you in learning the required material provided in EET470 class?

$16(89 \%)$

The FSC students used the same AMR M4 platform in two class sections of their EET 418: Microprocessor Interfacing and Control, that was offered in the fall quarters 2017 and 2018 respectively. As presented in Table 2, where FSC, EET 418 is the combined results of two class sessions in two different quarters of 2017 with 69 and 2018 with 61 students and taught by the same instructors, but different instructors in different section.

Table 2. FSC Students' Survey Results: EET418 in Years of 2017 and 2018

\begin{tabular}{|c|c|c|c|c|c|}
\hline \multirow[t]{2}{*}{$\#$} & \multirow{2}{*}{ Question } & \multicolumn{4}{|c|}{$\mathbf{N}=130$} \\
\hline & & \multicolumn{3}{|c|}{ Yes } & No \\
\hline 1 & $\begin{array}{l}\text { Do you have previous experience of using high level language such } \\
\text { as C or CPP? }\end{array}$ & \multicolumn{3}{|c|}{$97(75 \%)$} & $33(25 \%)$ \\
\hline 2 & $\begin{array}{l}\text { Did you use high level language in the interfacing control } \\
\text { application in other classes or curriculum? }\end{array}$ & \multicolumn{3}{|c|}{$75(58 \%)$} & $55(42 \%)$ \\
\hline 3 & $\begin{array}{l}\text { Do you think it is effective and necessary of using } \mathrm{C} \text { to do the } \\
\text { hardware interfacing control applications? }\end{array}$ & \multicolumn{3}{|c|}{$109(84 \%)$} & $21(16 \%)$ \\
\hline 4 & $\begin{array}{l}\text { Do you think the communications interfacing between the } \mathrm{C} / \mathrm{CPP} \\
\text { and ASM on an ARM M4 will be beneficial to you? }\end{array}$ & \multicolumn{3}{|c|}{$102(78 \%)$} & $28(22 \%)$ \\
\hline 5 & $\begin{array}{l}\text { After learning the materials in EET418, are you capable to use high } \\
\text { level language (C) and ASM in the bits and bytes control } \\
\text { applications? }\end{array}$ & \multicolumn{3}{|c|}{$88(68 \%)$} & $42(32 \%)$ \\
\hline 6 & $\begin{array}{l}\text { Do you like to see more applications of C/CPP in EET418? What } \\
\text { are those subjects? }\end{array}$ & \multicolumn{3}{|c|}{$97(75 \%)$} & $33(25 \%)$ \\
\hline \multirow[t]{2}{*}{7} & \multirow{2}{*}{$\begin{array}{l}\text { How much ARM M4 should be introduced in the EET418? } 20 \% \text {, } \\
50 \%, 100 \% \text {, or Not at all }\end{array}$} & $20 \%$ & $50 \%$ & $100 \%$ & \multirow[t]{2}{*}{$6(5 \%)$} \\
\hline & & $\begin{array}{c}16 \\
(12 \%)\end{array}$ & $\begin{array}{c}47 \\
(36 \%) \\
\end{array}$ & $\begin{array}{c}61 \\
(47 \%) \\
\end{array}$ & \\
\hline \multirow[t]{2}{*}{8} & \multirow[t]{2}{*}{ Do you think the $\mathrm{C}$ should be concentrate on PIC C or ARM M4? } & PIC & Both & ARM & \multirow[t]{2}{*}{$11(8 \%)$} \\
\hline & & $\begin{array}{c}9 \\
(7 \%) \\
\end{array}$ & $\begin{array}{c}53 \\
(41 \%) \\
\end{array}$ & $\begin{array}{c}57 \\
(44 \%) \\
\end{array}$ & \\
\hline 9 & $\begin{array}{l}\text { Do you think the } u C \text { Training System assisted you in learning the } \\
\text { required material provided in EET } 418 \text { class? }\end{array}$ & \multicolumn{3}{|c|}{$92(71 \%)$} & $38(29 \%)$ \\
\hline
\end{tabular}

The PVAMU Computer Engineering Technology majors also used the same ARM M4 and the same $u C$ Training System. The same questionnaire was given to these students and the assessment results are reported in Table 3. This is the first time where CPET courses included this new curriculum. The two co-requisite courses are senior level required courses.

Table 3. PVAMU Students' Survey Results: CPET4051/4053 in Year of 2018

\begin{tabular}{|c|c|c|c|}
\hline \multirow[t]{2}{*}{ \# } & \multirow{2}{*}{ Question } & \multicolumn{2}{|c|}{$\mathbf{N}=\mathbf{3}$} \\
\hline & & Yes & No \\
\hline 1 & $\begin{array}{l}\text { Do you have previous experience of using high level language such } \\
\text { as C or CPP? }\end{array}$ & $3(100 \%)$ & $0(0 \%)$ \\
\hline 2 & $\begin{array}{l}\text { Did you use high level language in the interfacing control } \\
\text { application in other classes or curriculum? }\end{array}$ & $1(33 \%)$ & $2(67 \%)$ \\
\hline 3 & $\begin{array}{l}\text { Do you think it is effective and necessary of using } \mathrm{C} \text { to do the } \\
\text { hardware interfacing control applications? }\end{array}$ & $3(100 \%)$ & $0(0 \%)$ \\
\hline 4 & $\begin{array}{l}\text { Do you think the communications interfacing between the C/CPP } \\
\text { and ASM on an ARM M4 will be beneficial to you? }\end{array}$ & $3(100 \%)$ & $0(0 \%)$ \\
\hline
\end{tabular}




\begin{tabular}{|c|c|c|c|c|c|}
\hline 5 & $\begin{array}{l}\text { After learning the materials in CPET4051/4053, are you capable to } \\
\text { use high level language (C) and ASM in the bits and bytes control } \\
\text { applications? }\end{array}$ & \multicolumn{3}{|c|}{$3(100 \%)$} & $\mathbf{0}(\mathbf{0 \%})$ \\
\hline 6 & $\begin{array}{l}\text { Do you like to see more applications of C/CPP in CPET4051/4053? } \\
\text { What are those subjects? }\end{array}$ & \multicolumn{3}{|c|}{$3(100 \%)$} & $\mathbf{0}(\mathbf{0 \%})$ \\
\hline \multirow{2}{*}{7} & \multirow{2}{*}{$\begin{array}{l}\text { How much ARM M4 should be introduced in the CPET } 4051 / 4053 ? \\
20 \%, 50 \%, 100 \% \text {, or Not at all }\end{array}$} & $20 \%$ & $50 \%$ & $100 \%$ & \multirow[t]{2}{*}{$\mathbf{0}(0 \%)$} \\
\hline & & $\begin{array}{c}0 \\
\mathbf{0} \\
(0 \%)\end{array}$ & $\begin{array}{c}3 \\
(100 \%) \\
\end{array}$ & $\begin{array}{c}0 \\
(0 \%) \\
\end{array}$ & \\
\hline \multirow{2}{*}{8} & \multirow{2}{*}{ Do you think the $\mathrm{C}$ should be concentrate on PIC C or ARM M4? } & PIC & Both & ARM & \multirow[t]{2}{*}{$\mathbf{0}(\mathbf{0 \%})$} \\
\hline & & $\begin{array}{c}\mathbf{0} \\
(0 \%)\end{array}$ & $\begin{array}{c}2 \\
(67 \%)\end{array}$ & $\begin{array}{c}1 \\
(33 \%)\end{array}$ & \\
\hline 9 & $\begin{array}{l}\text { Do you think the } u C \text { Training System assisted you in learning the } \\
\text { required material provided in CPET } 4051 / 4053 \text { classes? }\end{array}$ & \multicolumn{3}{|c|}{$3(100 \%)$} & $\mathbf{0}(\mathbf{0 \%})$ \\
\hline
\end{tabular}

This was the first time that Electrical and Computer Engineering students at PVAMU used the ARM M4 MCU hardware. The same survey questionnaires were distributed and completed for the assessment and presented in Table 4. Since ELEG 4253 is an engineering course, it contains a more theoretical approach to the content as compared to the hands-on exercises of the same MCU.

Table 4. PVAMU Students' Survey Results: ELEG4253 in Year of 2018

\begin{tabular}{|c|c|c|c|c|c|}
\hline \multirow[t]{2}{*}{ \# } & \multirow[t]{2}{*}{ Question } & \multicolumn{4}{|c|}{$N=9$} \\
\hline & & \multicolumn{3}{|c|}{ Yes } & No \\
\hline 1 & $\begin{array}{l}\text { Do you have previous experience of using high level language such } \\
\text { as C or CPP? }\end{array}$ & \multicolumn{3}{|c|}{$8(89 \%)$} & $1(11 \%)$ \\
\hline 2 & $\begin{array}{l}\text { Did you use high level language in the interfacing control } \\
\text { application in other classes or curriculum? }\end{array}$ & \multicolumn{3}{|c|}{$4(44 \%)$} & $5(56 \%)$ \\
\hline 3 & $\begin{array}{l}\text { Do you think it is effective and necessary of using } \mathrm{C} \text { to do the } \\
\text { hardware interfacing control applications? }\end{array}$ & \multicolumn{3}{|c|}{$8(89 \%)$} & $1(11 \%)$ \\
\hline 4 & $\begin{array}{l}\text { Do you think the communications interfacing between the C/CPP } \\
\text { and ASM on an ARM M4 will be beneficial to you? }\end{array}$ & \multicolumn{3}{|c|}{$8(89 \%)$} & $1(11 \%)$ \\
\hline 5 & $\begin{array}{l}\text { After learning the materials in ELEG4253, are you capable to use } \\
\text { high level language (C) and ASM in the bits and bytes control } \\
\text { applications? }\end{array}$ & \multicolumn{3}{|c|}{$5(56 \%)$} & $4(44 \%)$ \\
\hline 6 & $\begin{array}{l}\text { Do you like to see more applications of C/CPP in ELEG4253? } \\
\text { What are those subjects? }\end{array}$ & \multicolumn{3}{|c|}{$9(100 \%)$} & $\mathbf{0}(\mathbf{0 \%})$ \\
\hline \multirow{2}{*}{7} & \multirow{2}{*}{$\begin{array}{l}\text { How much ARM M4 should be introduced in the ELEG4253? } \\
20 \%, 50 \%, 100 \% \text {, or Not at all }\end{array}$} & $20 \%$ & $50 \%$ & $100 \%$ & \multirow[t]{2}{*}{$\mathbf{0}(\mathbf{0 \%})$} \\
\hline & & $\begin{array}{c}\mathbf{0} \\
(0 \%)\end{array}$ & $\begin{array}{c}6 \\
(67 \%) \\
\end{array}$ & $\begin{array}{c}3 \\
(33 \%)\end{array}$ & \\
\hline \multirow[t]{2}{*}{8} & \multirow[t]{2}{*}{ Do you think the C should be concentrate on PIC C or ARM M4? } & PIC & Both & ARM & \multirow[t]{2}{*}{$\mathbf{0}(\mathbf{0 \%})$} \\
\hline & & $\begin{array}{c}\mathbf{0} \\
(0 \%)\end{array}$ & $\begin{array}{c}7 \\
(78 \%)\end{array}$ & $\begin{array}{c}2 \\
(22 \%)\end{array}$ & \\
\hline 9 & $\begin{array}{l}\text { Do you think the } u C \text { Training System assisted you in learning the } \\
\text { required material provided in ELEG } 4253 \text { class? }\end{array}$ & \multicolumn{3}{|c|}{$9(100 \%)$} & $\mathbf{0}(\mathbf{0} \%)$ \\
\hline
\end{tabular}

Based on the review of the above survey data, ODU has over $88 \%$ overall responses that are in favor of using the ARM M4 and $\mathrm{C}$ as the programming language. $\mathrm{FSC}$ has $62 \%$, PVAMU/CPET has almost all, and PVAMU/ELEG has over $74 \%$ in favor in the same categories as ODU students. All the data indicate that the $u C$ Training System is a necessary hardware platform that should be used in class. This is particularly important to ODU students who took the EET 470 class in a distance learning, real-time, synchronous format. This means that the ODU students were required to complete their project designs and assignments with the specified 
hardware. Accordingly, the instructor only required students to turn in the $\mathrm{C}$ code design which was graded by the instructor using the same hardware platform used to evaluate the performance of the assignment. The required use of a common platform was a critical element in making the course distance delivery functional and successful. It can be inferred that the assessment from the ODU students showed a strong preference of $89 \%$ in survey question 9 on the $u C$ Training System to be used in this class, where FSC students are 92\% and PVAMU CPET and ELEG are all in preference in the same hardware platform. The data also demonstrates that almost all students at both ODU, FSC, and PVAMU prefer C-language over ASM coding when using complex microcontrollers for experimentation and project design. They also agree with using both PIC and ARM MCUs are necessary as teaching tools. This is in line with industry recommendations and preference for $\mathrm{C}$ language related to job employment.

\section{Lessons Learned with These Collaborated Efforts}

ODU has learned from these new curriculum efforts: (1) a simple microcontroller such as PIC16FXXX is appropriate to bridge the transition of students who follow the $2+2$ agreement between 4- and 2-year institutions and, (2) offer a second class right after the 2+2 such as ARM M2 microcontroller with $\mathrm{C}$ coding which is challenging for the students to follow and leads students to drop out of the elected course. A solution can be to add a transition class that can help students' better transition from ASM to C coding while using the same microcontroller (PIC16FXXX). This is also a retention issue for the necessary changes of the program curricula. Subsequently, more advanced topics such as ADC, DAC, SPI, $\mathrm{I}^{2} \mathrm{C}$, and wireless communication can be addressed with confidence before entering the ARM M4 complex environment. This led the addition of EET261, a new course added as a required course that can be directly transferred from community college to ODU. This new course, "Intro Microprocessor and Microcontroller" concentrates on PIC16FXXX microcontroller in ASM coding and peripheral controls of LEDs, LCD, Interrupts, $4 * 4$ Keypad, embedded system circuit designs and layout. The old EET320 will be revised with new content as EET320 (required course): "Advanced Microprocessor and Microcontroller" that still uses PIC16FXXX microcontroller but focuses on C coding with LCD, Interrupts, $4 * 4$ Keypad, SPI, $\mathrm{I}^{2} \mathrm{C}$, wireless communications, embedded system implementation in mechatronic applications. The senior elective course EET470 "Microcontroller System Designs" starts completely new class based on TI ARM M4 microcontroller and C coding for peripheral controls including SPI, $\mathrm{I}^{2} \mathrm{C}$, PWM, Interrupt, ADC, USB. It is believed with these course structural changes will assist students in better preparing for job challenges in embedded system design and mechatronic fields.

FSU has learned from these new curriculum efforts: (1) move EET251 from second year to third year offering can improve understanding concepts and practices addressed in EET418, (2) offer two or three simulation based labs such as Proteus simulation software before introducing hardware that can enhance the students' understanding of microcontrollers and microprocessors, and (3) add one or two EET251 lab(s) with C programming experiences can help student better transition from PIC16F84A to ARM M4 which is covered in EET 418.

With the help of this new curriculum and the common hardware platform, CPET students at PVAMU had the opportunity to practice embedded system hands-on experiments without undue stress in connecting basic peripheral interfacing circuits. The problem that we perceived was that it was difficult for students to write $\mathrm{C}$ program code for the ARM microcontroller because of the complexity of ARM technology. It will be helpful to introduce simple microcontroller, such as PIC16FXXX, in both ASM and C coding in some previous courses. The 
instructor will coordinate this practice of course revamping within CPET. The instructor will include these practices through revisions and additions of the class next time it offered in CPET at PVAMU.

The adoption of the $u C$ Training System and ARM M4 MCU enabled PVAMU Electrical and Computer Engineering students to implement more hands-on practice in a senior level computing course. The new curriculum was well developed, and students can follow the guidance to gain the knowledge and experience in a step by step manner. Simply stated, the $u C$ Training System made teaching easier and enabled the instructor to incorporate more instructional modules during class. Additionally, students increased their focus and attention on the microcontroller software design concepts and issues.

\section{Recommendations of Potential Adoption of the Development}

It would be a significant challenge for individual faculty members to plan, prepare, and develop new curriculum materials or implement new microcontroller platforms to meet the needs and challenges expected by industry. The purpose of this article and presentation is to disseminate the results of a collaborative study to the academic community that can use and share these experiences with others. Additionally, the goals of this presentation are directed toward the academic community and may include faculty and other interested parties that share a common interest in microcontroller or embedded system design and can speak the same technical language, ask questions, provide answers, and even collaborate on projects.

There are many situations where faculty professional development begins with a good start by attending a training workshop or seminar but end up with little or no further interest because there is no continuous support or follow-up. Sometimes it may simply be there is no one to talk to when there is a "glitch" in the technology or a technical problem. Even when technical support is available, there are times where the support person does not understand or care about academic issues and concerns. Often assistance that may be provided is not applicable or beyond the faculty member's capability to resolve the problem or issue. However, an effective LMS can provide the capability to address and resolve many issues and problems. Suggestions and solutions can be posted to the LMS and shared and updated through links to other faculty that can provide suggestions, guidance, or answers that lead to problem and issue solutions. This makes the problem-solving or trouble shooting much easier and less stressful. Since the academic community consists of faculty in the same or similar classes, the discussion can be more open and with less frustration. The researcher's experiences and successes lead us to recommend that readers try this LMS platform and use the same hardware, software, and experiments that has been developed and posted. Additionally, suggestions, recommendations, criticism, and modifications can provide a path toward making the LMS work more efficiently and effectively.

\section{Continuous Improvement of Teaching and Learning in Academic Community}

The curriculum development process for planning for new courses or revising existing courses is challenging. Generally, the development process takes considerable time and effort and additionally, its implementation stage is even longer. This article is a continuing effort as an example in developing new courses using a collaborative approach with common goals and outcomes. The collaborative process provides the opportunity to share evaluations, refine materials, and make appropriate corrections and adjustments as necessary. An added benefit in 
using a collaborative strategy is it can reduce the time and provide a wider review of materials that are created during the development process.

This approach offers an alternative model in the development, verification, evaluation, and implementation using a team effort and a LMS to disseminate the materials to the academic community. Thus, benefiting the broad community members and bringing the students more closely to the real world of work. The collaborative curriculum effort, as presented here, e.g. the course materials and lab modules are far from complete. However, it is expected that a continuous improvement will follow, and questions and suggestions are anticipated through the LMS. It is also expected that prospective users of these materials will request explanations about the content and hardware and even contribute to the development process thus resulting in a better product.

\section{Conclusion and Recommendation}

The curriculum development process takes a significant amount of time and effort to produce high-quality and effective materials. First, the instructor or developer must thoroughly learn and understand the theory and application of the new material. Second, the preparation of handouts, lecture materials, homework assignments, quizzes, and exams take additional time and energy to create.

This is particularly challenging when developing materials for laboratory classes as there are frequent glitches, unanticipated interference, or component issues that cause unintended outcomes and must be addressed and corrected at the last moment to continue the experiment. Imagine all of the factors that must come together to result in a realistic and effective experiment. The lab experiment content, software and hardware, miscellaneous components all must work together and conclude in the desired learning experience. Additionally, it is important to realize that in our ever-fast-changing technological era, it is necessary to offer degree programs that reflect the changes in industry and the job market. This realization in a large measure is the responsibility of the instructor to update and maintain course and program relevance to the real world.

The intent of changes of the course content were based on the suggestions from engineers and technical sales representatives during annual ASEE conferences on the skills needed in the embedded systems design and/or mechatronics fields. Further, it was recommended that students have programming skill in both ASM and $\mathrm{C}$ along with hardware understanding on different manufacturer parts in system design and application. These recommended changes took place over a period of four years to actively implement them. Because of an NSF funded project in 2012 - 2013 [16], an academic community that share a common interest in embedded systems design was established. Additionally, an existing development platform enabled the feasibility of

a collaborative curriculum development project. The collaborative initiative, shared interests, and common development platform became the foundation of the curriculum development project.

The other outcome of this collaboration is the distance delivery either between faculty-tofaculty on curriculum or project or faculty-to-student in lecture or lab activities. Once this connection has been established, the sharing, using, improving, and changing of all the developed concepts become easier without geographical limitation. Certainly, any unexpected incident or technical difficulty can be easily resolved among faculty or students with simple Q and A, email, or traditional phone calls. Additionally, real-time video conferencing can be added easily whenever there is a need to resolve more complex problems and issues. 


\section{References}

1. S. Hsiung and F. Feng, "What does it take to delivery hands-on courses?". Proceedings of the 2015 American Society for Engineering Education Annual Conference \& Exposition. Engineering Technology Division, Session 12044, Seattle, Washington, June14-17, 2015.

2. L. Lewis, K. Snow, E. Farris, and D. Levin, “Distance Education at Postsecondary Institutions: 1997-98 (NCES) 2000-013.” Washington, DC: National Center for Education Statistics, 1999.

3. G.R., Morrison and S. M. Ross, "Designing Effective Online Instruction. In R. Luppicini (Ed.), Learning Communities in Online Education." Charlotte, NC: Information Age Publishing: 75-85, 2007.

4. S. Hsiung, X. Lijain, J. Feng, and I. Marjaneh. "Collaborated Efforts in TI ARM M4/32Bits Microcontroller Curricula Developments and Assessments”. Proceedings of the 2018 American Society for Engineering Education Annual Conference \& Exposition. Engineering Technology Division, Session 22446, Salt Lake, Utah, June 24-27, 2018.

5. COSMIAC, January 30, 2018. [Online]. Available: http://cosmiac.org/about-us/

6. Texas Instruments, Getting Started with Tiva C Series TM4C123G LaunchPad, http://processors.wiki.ti.com/index.php/Getting_Started_with_the_TIVA ${ }^{\text {TM }}$ _C_Series_TM4C123G_LaunchPad

7. Texas Instruments, Tiva ${ }^{\mathrm{TM}} \mathrm{C}$ Series TM4C123G LaunchPad Evaluation Board, User's Guide, 2013.

8. Texas Instruments, Tiva Ware Peripheral Driver Library, User's Guide, 2016.

9. J. Valvano, Embedded Systems: Real-Time Interfacing to the Arm Cortex-M3, ISBN: 978-1463590154, 2011.

10. J. Valvano, Embedded Systems: Real-Tine Interfacing to ARM Cortex-M Microcontrollers, $2^{\text {nd }}$ Edition, ISBN: 1463590156, 2016.

11. M. Mazidi, S. Chen, S. Naimi, "TI TIVA ARM Programming for Embedded Systems: Programming ARM Cortex-M4 TM4C123G with C”, 2017, ISBN 9780997925920, Amazon.com

12. LMS, January 30, 2018. [Online]. Available: http:// http://www.ucdistancetraining.org/moodle/

13. S. Hsiung, J. Ritz, M, R. Jones, J. Eiland, "Design and Evaluation of a Microcontroller Training System for Hands-on Distance and Campus-Based Classes." Journal of Industrial Technology 2010; 26(3): 2-8.

14. CCS, Texas Instrument Code Composer Studio, June 30, 2018. [Online]. Available: http://www.ti.com/tool/ccstudio

15. 25LC256, 256K, SPI EEPROM, January 30, 2019. [Online]. Available: http://www.microchip.com/wwwproducts/en/en023856

16. MRF24J40MA, 2.4GHz Wireless Transceiver Module, January 30, 2019. [Online]. Available: http:/www.microchip.com/wwwproducts/en/MRF24J40MA

17. TCN25A, I²C Temperature Sensor, January 30, 2019. [Online]. Available: http://www.microchip.com/wwwproducts/en/TCN75A

18. Adobe Connect, Adobe Connect Video Conferencing Meeting, January 30, 2019. [Online]. Available: http://buyconnect.adobe.com/store/adbecnn/en_US/Content/pbpage.pd-meetings

19. S. Hsiung, J. Ritz, F. Jao, and E. Yaprak, "Delivery of Hands-on Technical Courses through Real-Time Distance Learning". Proceedings of the 2014 American Society for Engineering Education Annual Conference \& Exposition. Engineering Technology Division, Session 8904, Indianapolis, Indiana, June15-18, 2014. 